\title{
Soluções de condicionamento para conservação pós-colheita de inflorescências de copo-de-leite armazenadas em câmara fria
}

\author{
Conditioning solutions for post harvest conservation of calla lily in cold chamber
}

\author{
Elka Fabiana Aparecida AlmeidaI Patrícia Duarte de Oliveira Paiva ${ }^{\text {II }}$ \\ Luiz Carlos de Oliveira Lima ${ }^{\text {III }}$ Maria Leandra Resende ${ }^{\text {II }}$ \\ Thaísa Silva Tavares ${ }^{\text {II }}$ Daniella Nogueira Moraes Carneiro ${ }^{\text {II }}$ \\ Juliana Fonseca $^{\mathrm{IV}}$ Renato Paivav
}

\begin{abstract}
- NOTA -
RESUMO

As informações sobre a conservação pós-colheita de copo-de-leite são escassas, apesar da sua importância comercial. Este trabalho teve como objetivo testar soluções de condicionamento para aumentar a durabilidade dessas inflorescências. Assim, testou-se o efeito do tratamento das hastes de copo-de-leite em soluções de condicionamento com hipoclorito de sódio (2\%), ácido cítrico (200mg $\left.\mathrm{L}^{-1}\right)$ e cloreto de cálcio (1000mg $\left.\mathrm{L}^{-1}\right)$. Avaliou-se também a influência da imersão pré-armazenamento das inflorescências em solução com Hidrosan ${ }^{\circledR}$ e a utilização deste conservante em solução de condicionamento das hastes para armazenamento em câmara fria. As inflorescências foram avaliadas diariamente quanto à durabilidade a partir do critério de classificação estabelecido (classes A1, A2, B e C) e pela medida do comprimento e largura da espata. O pré-tratamento das inflorescências em Hidrosan ${ }^{\circledR}$ ou a colocação das hastes neste conservante em câmara fria ou nos demais produtos não influenciaram na durabilidade das inflorescências de copo-de-leite, que apresentaram uma longevidade total de 11 dias. Os diferentes produtos avaliados não influenciaram na largura e no comprimento da espata. Observou-se que, independentemente

ABSTRACT

Information on post harvest conservation of calla lily is rare despite its commercial importance. This study was aimed at testing different conditioning solutions in order to increase inflorescence durability. The maintenance of calla lily stems on sodium hypochlorite (2\%), citric acid (200mg $\left.\mathrm{L}^{-1}\right)$ and calcium chlorate $\left(1000 \mathrm{mg} \mathrm{L}^{-1}\right)$ solutions was evaluated. The influence of a stem pre-storage immersion in Hidrosan ${ }^{\circledR}$ solution, as well as its use as a conditioning solution during storage in cold chamber was also evaluated. Inflorescences were daily evaluated for durability using an established classification criteria (classes A1, A2, B and C) and measurements of spathe length and width. Inflorescences treated with Hidrosan ${ }^{\circledR}$ or the maintenance of stems in this product or in any of the tested solutions showed no effect on calla lily's inflorescences durability which presented a total longevity of eleven days. The different conditioning solutions evaluated had no effect on spathe length and width. Regardless the conditioning solutions, spathe width and length increased until the $7^{\text {th }}$ and $8^{\text {th }}$ days, respectively. Increase in spathe dimension characterizes the opening process and its reduction indicates senescence by wilting.
\end{abstract} dos tratamentos, a largura da espata aumentou até o 7o dia e

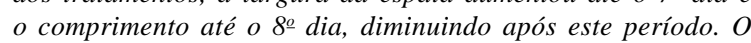
aumento das dimensões da espata caracteriza o processo de abertura e a redução da mesma indica a senescência pela murcha.

Palavras-chave: Zantedeschia aethiopica, durabilidade, armazenamento.
Key words: Zantedeschia aethiopica, durability, storage.

O copo-de-leite (Zantedeschia aethiopica Spreng) é uma espécie cultivada para corte de flores, sendo bastante apreciada para composição de arranjos

'Empresa de Pesquisa Agropecuária de Minas Gerais, EPAMIG/CTSM/FERN, BR 494, Km 2, Colônia do Bengo, CTAN, 36300000, São João Del Rei, MG, Brasil. E-mail: elka@epamig.br. Autor para correspondência.

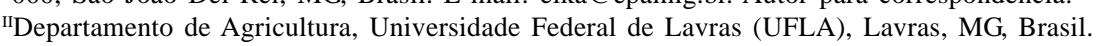

IIIDepartamento de Ciências dos Alimentos, UFLA, Lavras, MG, Brasil.

${ }^{\mathrm{IV}}$ Departamento de Engenharia Florestal, UFLA, Lavras, MG, Brasil.

vepartamento de Biologia, UFLA, Lavras, MG, Brasil. 
florais. No entanto, apresenta curta durabilidade, a qual pode ser melhorada com o armazenamento em câmara fria sob baixas temperaturas e o uso de diferentes soluções de manutenção (NOWAK \& RUDNICKI, 1990). Baixas temperaturas diminuem a perda de água, a ocorrência de infecções bacterianas e fúngicas e ainda inibem os diferentes processos relacionados à senescência (NOWAK \& RUDNICKI, 1990; GORSEL, 1994).

Para composição da solução de manutenção das flores, durante o período de armazenamento, vários produtos podem ser utilizados. Dentre esses, têm sido recomendados os que possuem ação bactericida, como hipoclorito de sódio, que agem purificando a água e inibindo infecções bacterianas nos vasos condutores que impedem a absorção de água. Também, para essa mesma função, produtos germicidas podem ser utilizados (PAULIN, 1983; NOWAK \& RUDNICKI, 1990). Ainda pode-se adicionar às soluções cloreto de cálcio, que atua atrasando a senescência das membranas ou antioxidantes, como ácido cítrico (POOVAIAH, 1986; NOWAK \& RUDNICKI, 1990).

Este trabalho teve como objetivo avaliar os produtos hipoclorito de sódio, cloreto de cálcio, ácido cítrico e Hidrosan ${ }^{\circledR}$, identificando os mais eficientes para serem utilizados na composição das soluções de manutenção de forma a proporcionar maior conservação do copo-de-leite após a colheita.

Para os experimentos, foram utilizadas inflorescências de copo-de-leite cultivadas a campo. Realizou-se a colheita das hastes de copo-de-leite no período da manhã, e transportando-as em seguida para o laboratório. O ponto de colheita utilizado foi o das hastes com inflorescências no estádio totalmente aberto, mas antes de a ponta da espata enrolar-se para baixo e com a espádice sem a presença de pólen (SALINGER, 1991; NOWAK \& RUDNICKI, 1990).

No primeiro experimento, realizado em março de 2004, foram testadas três soluções para condicionamento das inflorescências: solução contendo $2 \%$ de hipoclorito de sódio ( $\mathrm{NaClO})$, solução de $1.000 \mathrm{mg} \mathrm{L}^{-1}$ de cloreto de cálcio $\left(\mathrm{CaCl}_{2}\right)$, solução de 200 $\mathrm{mg} \mathrm{L}^{-1}$ de ácido cítrico, testemunha: água (potável). A cada dois dias foram realizadas trocas das soluções para evitar que se tornassem turvas. Utilizou-se delineamento inteiramente casualizado, com oito repetições e três inflorescências por parcela.

No segundo experimento, realizado em setembro de 2004, utilizou-se o germicida Hidrosan ${ }^{\circledR}$ (comercializado na forma de pastilha com $5 \mathrm{~g}$, a qual foi dissolvida em 15 litros de água). O experimento foi formado por quatro tratamentos constituindo um fatorial 2x2. Os tratamentos foram constituídos de dois procedimentos após a colheita: imersão total das inflorescências na solução com Hidrosan ${ }^{\circledR}$ por 30 minutos e o controle, que não recebeu a imersão no produto. Utilizaram-se duas formas de condicionamento das bases das hastes dentro da câmara fria UR 91\%: em solução de Hidrosan ${ }^{\circledR}$ (na mesma concentração da imersão) ou água (potável). Conforme comumente realizado por produtores, a solução de conservação foi trocada sempre que essa se apresentava turva. Dessa forma, avaliou-se o intervalo de dias em que houve necessidade de troca para cada solução estudada. O experimento foi instalado em delineamento inteiramente casualizado, com cinco repetições e três inflorescências por parcela.

As inflorescências permaneceram por dez dias dentro da câmara fria ( $4^{\circ} \mathrm{C}$, UR 91\%, no escuro), quando foram retiradas e mantidas em temperatura ambiente (média de $23^{\circ} \mathrm{C}$ ) por mais cinco dias. Todas as inflorescências foram avaliadas diariamente.

Considerando não existir nenhum padrão de qualidade estabelecido para a comercialização de inflorescências de copo-de-leite semelhante aos já determinados para outras espécies pelo Instituto Brasileiro de Floricultura (Ibraflor), elaborou-se um padrão baseado nos princípios adotados pelo Ibraflor, para avaliação da qualidade das inflorescências após os tratamentos testados:

CLASSE A1: inflorescências túrgidas, ponta da espata inclinada, ausência de rugas ou necroses;

CLASSE A2: inflorescências túrgidas, base da espata levemente enrolada para baixo, ausência de rugas ou necroses;

CLASSE B: inflorescências túrgidas, ponta da espata levemente enrolada para baixo, presença de rugas, ausência de necroses;

CLASSE C: inflorescências murchas, ponta da espata enrolada para baixo, presença de necrose.

Dessa forma, as avaliações consistiam na classificação de qualidade estabelecida, número de dias que permaneceram em cada classe, comprimento e largura da espata e presença de pólen.

A solução contendo hipoclorito de sódio proporcionou menor durabilidade das inflorescências de copo-de-leite nas classes A1+A2 (qualidade ideal para comercialização), em relação à testemunha (água) ou à solução de cloreto de cálcio, ou ácido cítrico, que não diferiram entre si. A concentração de hipoclorito de sódio utilizada pode ter sido elevada ou o período em que as inflorescências permaneceram na solução pode ter sido longo demais, o que proporcionou efeito tóxico às mesmas, interferindo na qualidade. Estes resultados concordam com as afirmações de NOWAK \& RUDNICKI, (1990) sobre a utilização de hipoclorito 
de sódio. Segundo esses autores, as flores-de-corte não devem permanecer por um período muito prolongado em contato com o hipoclorito de sódio, pois o cloro pode ser prejudicial às hastes das flores.

Analisando-se o número de dias em que as inflorescências permaneceram na classe $\mathrm{A} 1+\mathrm{A} 2+\mathrm{B}$ (representa a longevidade total das inflorescências), não se verificou diferença entre as soluções testadas. As inflorescências permaneceram, em média, 11 dias nesta classe.

Os diferentes produtos utilizados não influenciaram no comprimento e na largura da espata. Apenas os dias de observação interferiram nas dimensões. A largura da espata aumentou progressivamente, em média, até o $7^{0}$ dia, diminuindo após este período (Figura 1A). Já o comprimento da espata aumentou até o $8^{\circ}$ dia, diminuindo também após este período (Figura 1B). Essa redução caracteriza o início do processo de senescência, sendo que, no $7^{\circ}$ e no $8^{\circ}$ dia, as inflorescências ainda estavam armazenadas em câmara fria.

O copo-de-leite não respondeu ao tratamento com ácido cítrico, que atua como antioxidante, ao contrário do que já foi observado em gérberas utilizando na solução de manutenção $150 \mathrm{mg} \mathrm{L}^{-1}$ e do que é recomendado para rosas, $500 \mathrm{mg} \mathrm{L}^{-1}$ (KADER \& ROGERS, 1986; NOWAK \& RUDNICKI, 1990).

Para copo-de-leite também não houve influência do fornecimento de cálcio para aumentar a durabilidade das inflorescências, ao contrário dos resultados obtidos por HALEVY et al. (2001) em rosas. Isso pode ser devido à baixa mobilidade deste nutriente ao longo da haste floral, pois o cálcio é um elemento pouco móvel (MALAVOLTA, 1980). ao fato de a concentração de cloreto

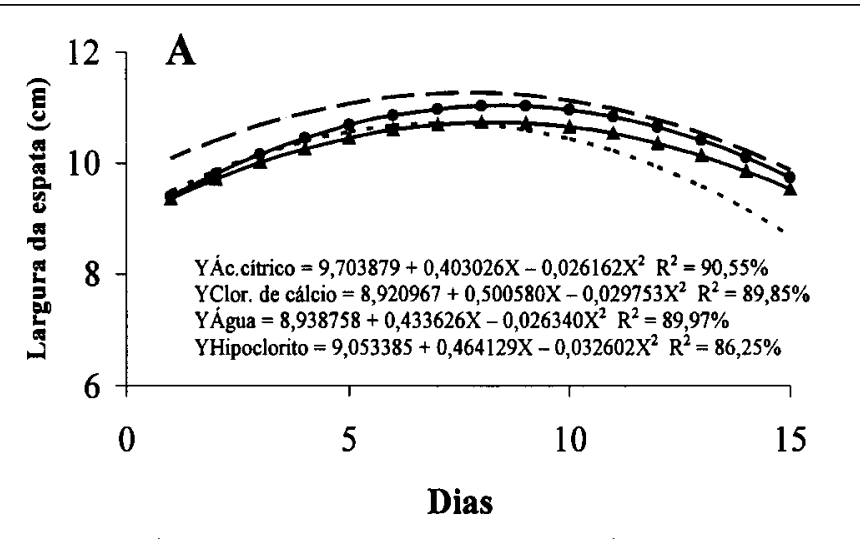

--- Ác. citrico $\longrightarrow$ Cior. de cálcio $\longrightarrow$ Água $-\cdots \cdot$ - Hipoclorito

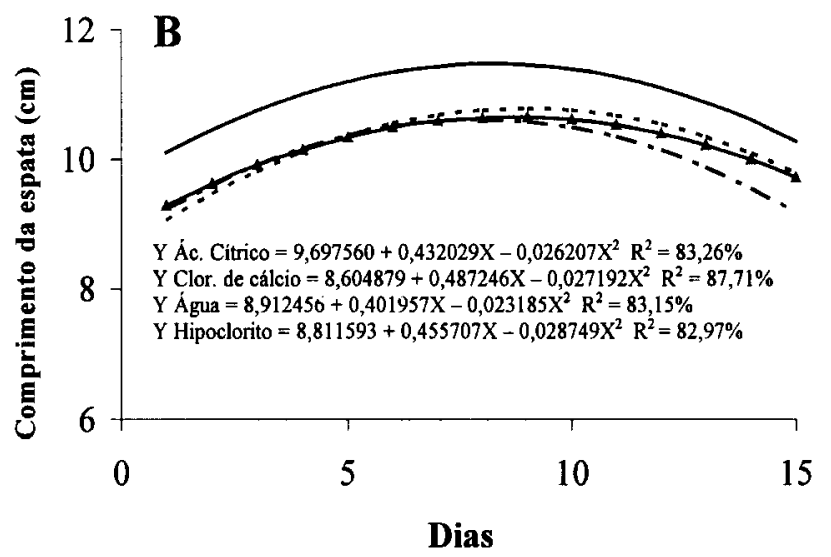

$\longrightarrow$ Ác. cítrico $\cdots$. Clor. de cálcio $\longrightarrow$ Água $-\cdots-$ Hipoclorito

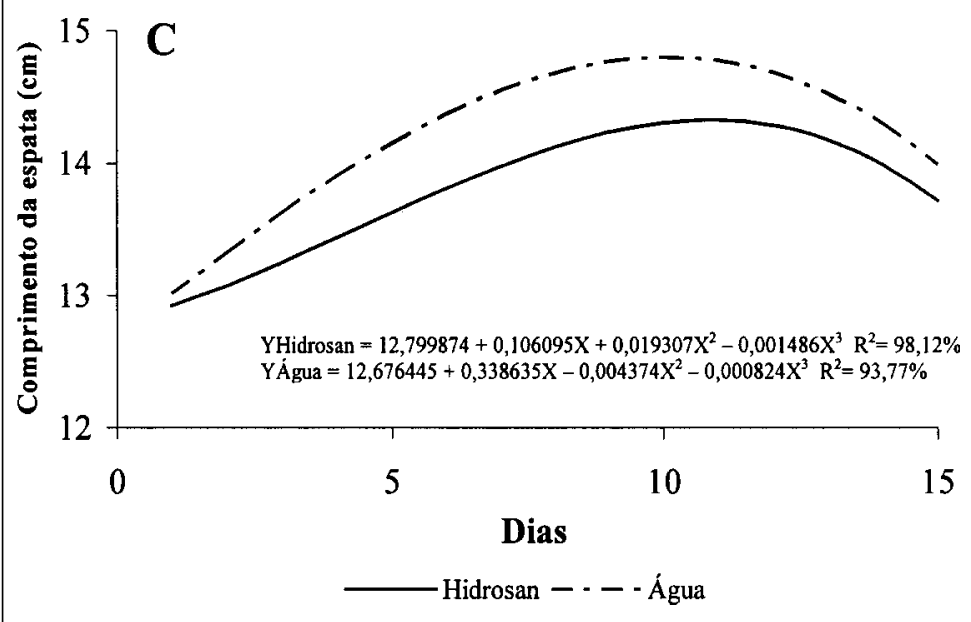

Figura 1 - Largura e comprimento $(\mathrm{cm})$ da espata de inflorescências de copo-deleite em função dos dias de avaliação, sendo 10 dias dentro da câmara fria e 5 dias em temperatura ambiente. 
de cálcio utilizada neste experimento (1000 $\left.\mathrm{mg} \mathrm{L}^{-1}\right)$ ter sido insuficiente para a espécie.

Muitos produtores têm utilizado hipoclorito de sódio e água como solução preservativa para a conservação pós-colheita de crisântemo (QUEIROZ et al., 2003), gérbera (NOWAK \& RUDNICKI, 1990) e também para rosas. O copo-de-leite não respondeu à utilização de hipoclorito de sódio na solução de manutenção.

No segundo experimento, testou-se o efeito do produto Hidrosan (germicida que apresenta em sua composição dicloro isocianurato de sódio, uma fonte de cloro orgânico muito utilizada para inibir o desenvolvimento de bactérias e outros microrganismos. Observou-se que a utilização do produto Hidrosan ${ }^{\circledR}$, na forma de solução para imersão total das inflorescências ou como solução de manutenção dentro da câmara fria, não interferiu na durabilidade do copode-leite. O período em que as hastes permaneceram nas classes de qualidade A1, A2 ou B foi, em média, de 5, 3 e 2 dias, respectivamente. Também não houve efeito do produto Hidrosan) na variação de largura da espata.

As inflorescências que foram dispostas em solução com Hidrosan ${ }^{\circledR}$ apresentaram menor aumento no comprimento da espata, permanecendo por um período maior nesta fase de abertura (Figura 1C). Apenas a partir do $11^{\circ}$ dia, foi verificada uma diminuição no comprimento da espata, indicando início de senescência da inflorescência. Para as inflorescências mantidas em água, observou-se um aumento no comprimento da espata apenas até o $10^{\circ}$ dia. A partir deste período, houve diminuição no comprimento da espata. Por meio destas observações, foi possível verificar que as inflorescências dispostas na água começaram a murchar mais precocemente que as inflorescências dispostas na solução com Hidrosan ${ }^{\circledR}$. O Hidrosan ${ }^{\circledR}$ foi eficiente na composição da solução de manutenção das hastes de copo-de-leite, por ter possivelmente atuado na inibição do desenvolvimento de microrganismos que podem ter contaminado as inflorescências ainda no campo.

Apesar do efeito positivo proporcionado pelo Hidrosan ${ }^{\circledR}$ às inflorescências de copo-de-leite, observou-se que, quando as hastes foram dispostas neste produto, a espádice apresentou liberação de pólen mais precocemente, ou seja, aos sete dias após a colheita. Já para as hastes dispostas na água, este fator foi verificado a partir do 9o dia.
Não houve necessidade de troca da solução de conservação durante o armazenamento quando se utilizou o produto Hidrosan ${ }^{\circledR}$, devido ao aspecto cristalino que essa apresentou durante todo o experimento (15 dias). Porém, a água pura necessitou ser trocada a cada dois dias, pois apresentava aspecto turvo, situação indesejável. O maior intervalo de troca de água é muito interessante para os produtores, pois diminui a mão-de-obra no período de armazenamento das flores.

Os resultados indicam que nenhuma das soluções testadas influencia a durabilidade das inflorescências de copo-de-leite, sendo que o produto Hidrosan ${ }^{\circledR}$ proporciona aspecto mais cristalino à solução durante todo o período de armazenamento.

\section{REFERÊNCIAS}

GORSEL, R.V. Postharvest technology of imported and transshipped tropical floricultural commodities. HortScience, Alexandria, v. 29, n.9, p.979-981, 1994.

HALEVY, A.H. et al. Calcium in regulation of postharvest life of flowers. Acta Horticulturae, Amsterdam, v.543, p.345351, 2001.

KADER, A.H.; ROGERS, M.N. Postharvest treatment of Gerbera Jamesonii. Acta Horticulturae, Amsterdam, v.181, p.169-177, 1986.

MALAVOLTA, E. Elementos de nutrição mineral de plantas. São Paulo: Agronômica Ceres, 1980. 254p.

NOWAK, J.; RUDNICKI, R.M. Postharvest handling and storage of cut flowers, florist greens and potted plants. Portland: Timber, 1990. 210p.

PAULIN, A. Improvement in the preservation of cut flowers. Acta Horticulturae, Amsterdam, v.138, p.299-305, 1983.

POOVAIAH, B.W. Role of calcium in prolonging storage life of fruits and vegetables. Food Technology, Chicago, v.40, n.5, p.86-99, 1986.

QUEIROZ, M.B. et al. Caracterização das operações póscolheita de crisântemo (Dendratema Grandiflora) no estado do Ceará. In: CONGRESSO BRASILEIRO DE FLORICULTURA E PLANTAS ORNAMENTAIS, 14.; CONGRESSO BRASILEIRO DE CULTURA DE TECIDOS DE PLANTA, 2003, Lavras. Anais... Lavras: UFLA/FAEPE, 2003. p.53.

SALINGER, J.P. Producción comercial de flores. Zaragoza: Acribia, 1991. 371p. 